\title{
Analisis Perbandingan Biaya pada Pekerjaan Pengerukan di Alur Pelabuhan Bandar Bakau Jaya Banten
}

\author{
Aden Firdaus, Muhammad Rizkiansyah, Yessi Nirwana \\ Jurusan Teknik Sipil, Fakultas Teknik Sipil dan Perencanaan ITENAS, Bandung, Indonesia \\ Email: adenfirdaus@itenas.ac.id, rizkiansyah.m@gmail.com, yessi@itenas.ac.id
}

Received 07 April 2020| Revised 05 Juli 2020 | Accepted 12 Juli 2020

\begin{abstract}
ABSTRAK
Pelabuhan Bandar Bakau Jaya yang terletak di Provinsi Banten saat ini dapat melayani kapal yang berjenis 5.000 DWT, dan rencananya akan melayani kapal 10.000 DWT. Pekerjaan pengerukan akan dilakukan pada Alur Pelabuhan dengan dimensi panjang $2.391 \mathrm{~m}$ dengan jenis tanah adalah tanah halus berpasir. Tujuan dari penelitian ini adalah membandingkan biaya dan waktu pelaksanaan dari masingmasing jenis kapal keruk yang dapat melakukan pekerjaan pengerukan dengan kondisi tanah yang ada di alur pelabuhan. Metode yang digunakan adalah dengan memperhitungkan berapa lama waktu pekerjaan pengerukan sehingga didapatkan biaya dari masing-masing jenis kapal keruk. Hasil dari analisis didapatkan 3 jenis kapal keruk yaitu, TSHD dalam waktu 2,11 bulan dan biaya Rp27.316.912.819,63, SD dalam waktu 8,34 bulan dan biaya Rp27.887.202.652,35, dan CSD dalam waktu 6,08 bulan dan biaya Rp37.995.671.214,00. Jenis kapal keruk yang paling efisien untuk pekerjaan pengerukan di alur pelabuhan ini adalah TSHD dengan 7 tugboat dan barge.
\end{abstract}

Kata kunci: pengerukan, alur pelayaran, kapal keruk

\begin{abstract}
Bandar Bakau Jaya Port, located in Banten Province, currently serves 5,000 DWT vessels, and it is planned to serve 10,000 DWT vessels. Dredging work will be carried out on the Port Channel with a dimension of 2,391 $\mathrm{m}$ in length with a fine sandy soil type. The purpose of this study is to compare the cost and implementation time of each type of dredger that can carry out dredging work with existing soil conditions in the port channel. The method used is to calculate how long the dredging work is so that the cost of each type of dredger is obtained. The results of the analysis found 3 types of dredges namely, TSHD in 2.11 months and costs Rp27,316,912,819.63, SD in 8.34 months and costs Rp27,887,202,652.35, and CSD in 6, 08 months and costs Rp37,995,671,214.00. The most efficient type of dredger for this work is TSHD with 7 tugboats and barges.
\end{abstract}

Keywords: dredging, fairway, dredger 


\section{PENDAHULUAN}

Pelabuhan Bandar Bakau Jaya merupakan salah satu dari pelabuhan umum yang ada di Indonesia, dibangun oleh PT. Bandar Bakau Jaya. Pelabuhan ini terletak di Desa Margagiri, Kecamatan Bojonegara, Kabupaten Serang, Provinsi Banten. Jenis kapal yang dapat dilayani pada saat ini di pelabuhan Bandar Bakau Jaya adalah kapal yang berjenis 5.000 DWT (deadweight tonnage), dengan dimensi kapal (Panjang LOA (Length Over All) $=109 \mathrm{~m}$; Lebar $=16,4 \mathrm{~m} ;$ Draft $=6,8 \mathrm{~m})$. Rencananya pelabuhan ini akan melayani kapal yang berjenis 10.000 DWT dengan dimensi kapal (Panjang LOA = $140 \mathrm{~m}$; Lebar = 18,7 m; Draft = 8,1 m).

Pekerjaan pengerukan perlu dilakukan pada alur pelabuhan ini agar pelabuhan dapat melayani kapal berjenis 10.000 DWT [1]. Untuk memenuhi kedalaman alur pelabuhan yang dibutuhkan, pelaksanaan pengerukan dengan biaya yang relatif besar pada komponen kapal keruk harus dilakukan analisis perbandingan biaya agar dapat menentukan kapal keruk (dredger) mana yang paling murah [2].

Tujuan dari penelitian ini adalah agar dapat membandingkan biaya dan waktu pelaksanaan dari masing-masing jenis kapal keruk yang dapat melakukan pekerjaan pengerukan dengan kondisi tanah yang ada di alur pelabuhan. Hal ini akan memberikan alternatif dari beberapa jenis kapal keruk yang ada dan memudahkan dalam menentukan kapal keruk mana yang akan digunakan dalam pekerjaan pengerukan di alur Pelabuhan Bandar Bakau Jaya Banten ini.

\section{TINJUAN PUSTAKA}

\subsection{Pelabuhan}

Pada dasarnya pelabuhan adalah suatu daerah perairan yang terlindung dari gelombang laut. Biasanya pelabuhan digunakan sebagai tempat kapal berlabuh, baik kapal barang, kapal penumpang, kapal alat berat, dan lainnya. Pelabuhan juga memerlukan fasilitas bongkar muat seperti tambat, kran, gudang, terminal, dan sebagainya. Selain itu, pelabuhan berfungsi sebagai penghubung antar daerah. Daerah yang dimaksud dapat mempunyai hubungan ekonomi, sosial, maupun pertahanan [3].

\subsection{Alur Pelayaran}

Alur pelayaran adalah bagian dari perairan yang alami maupun buatan yang digunakan sebagai lintasan arus lalu lintas kapal dengan kedalaman, lebar dan hambatan pelayaran lainnya yang dianggap aman untuk dilayari [4]. Alur pelayaran berfungsi untuk mengarahkan kapal yang akan memasuki pelabuhan. Kondisi air di alur pelayaran dan kolam pelabuhan harus tenang terhadap pengaruh gelombang dan arus yang datang. Ukuran kapar terbesar yang akan memasuki pelabuhan menjadi acuan untuk merencanakan alur pelayaran pada pelabuhan, beserta kondisi meteorologi dan oseanografi. Kapal yang akan masuk ke alur pelayaran harus mengurangi kecepatan hingga akhirnya berhenti di dermaga [5].

\subsection{Sedimentasi dan Volume Sedimen}

Sedimentasi terjadi karena adanya pengangkutan endapan melalui arus air laut maupun air tawar dan biasanya terjadi terus menerus [6]. Sedimentasi ini dapat terjadi di daerah sungai maupun di daerah pantai. Arus air laut maupun sungai yang kuat dapat membawa pasir sampai dengan batuan kecil. Pada saat arus melemah, partikel-partikel tersebut mengendap dan terbentuklah sedimen.

Untuk mengetahui volume sedimen di alur pelayaran pelabuhan Bandar Bakau Jaya Banten ini, telah dilakukan perhitungan pada penelitian sebelumnya [7] menggunakan Pemodelan Hidrodinamika dan Sedimen Transpor dengan bantuan piranti lunak MIKE 21. Parameter dasar yang ditinjau pada penelitian sebelumnya meliputi data batimetri dan periode simulasi. Parameter hidrodinamika yang ditinjau pada penelitian sebelumnya meliputi elevasi awal muka air, kondisi bataas wilayah pemodelan, dan beberapa koefisien seperti koefisien kekasaran (manning/chezy) dan koefisien 
kekentalan (smagorinsky). Parameter transportasi sedimen yang ditinjau pada penilitian sebelumnya meliputi data hidrodinamika, data diameter butir sedimen, dan data konsentrasi sedimen.

\subsection{Pengerukan}

Pengerukan (dredging) adalah mengambil tanah atau material dari lokasi di dasar air, perairan dangkal seperti danau, sungai, muara ataupun laut dangkal, dan memindahkan atau membuangnya ke lokasi lain [4]. Tujuan pengerukan antara lain untuk pelayaran, konstruksi dan reklamasi, perbaikan lingkungan, pengendali banjir, dan pertambangan.

Menurut Eisma [5], secara garis besar pengerukan dibagi menjadi 3 jenis, yaitu pengerukan Awal (Capital Dredging), pengerukan Perawatan (Maintenance Dredging), dan pengerukan Ulang (Remedial Dredging). Proses pengerukan dibagi ke dalam 4 tahap berdasarkan Bray dan Cohen [6], yaitu penggalian, transportasi vertikal, transportasi horizontal, dan pembuangan ke lokasi pembuangan atau penggunaan material kerukan. Pada penelitian ini, jenis pekerjaan pengerukannya adalah pengerukan awal (capital dredging).

\subsection{Kapal Keruk}

Kapal keruk (dredger) digunakan untuk memindahkan material keruk dari satu tempat ke tempat lain. Tipe kapal keruk yang dikembangkan dapat dikelompokkan dalam 3 grup utama, yaitu mechanical dredger, hydraulic dredger, dan peralatan keruk tipe lainnya (dredging plants). Berikut adalah jenisjenis kapal keruk yang sering digunakan dalam proyek pengerukan.

Trailing Suction Hopper Dredger (TSHD) adalah kapal keruk dengan produktivitas yang cukup tinggi $\left(12.500 \mathrm{~m}^{3} / \mathrm{jam}\right)$. Kapal ini memiliki alat gerak sendiri dan mempunyai hopper yang dapat mengangkat material hasil sedotan dari dasar laut melalui drag head dan pipa.

Grab Dredger mempunyai clamshell grab. Ini tersambung dengan crane. Crane ini menumpang di atas ponton atau kapal lainnya yang ikut dalam pekerjaan ini. Hasil kerukan dimasukkan ke barge untuk selanjutnya diangkut ke lokasi pembuangan.

Backhoe Dredger (BHD) adalah dari excavator darat yang dipasang di atas kapal ponton yang selanjutnya dioperasikan menjadi kapal keruk. Ukuran excavator dan ember dapat disesuaikan tergantung dari jenis material yang akan dikeruk.

Bucket Ladder Dredger adalah kapal keruk yang mempunyai rantai ember yang dapat mengeruk dasar laut dan kemudian menuangkannya ke kapal tongkang untuk diangkut.

Suction Dredger (SD) adalah kapal keruk dengan fungsi hisap yang cocok untuk menyedot bahan yang relatif tidak padat dan langsung dapat menyalurkan hasil kerukan ke tongkang atau ke pantai yang berdekatan. Kapal ini memiliki produktivitas pengerukan material sampai dengan $2500 \mathrm{~m} / \mathrm{jam}$.

Cutter Suction Dredger (CSD) adalah kapal keruk yang dapat memotong, menghancurkan, dan sekaligus menyedot material keruk yang ada di dasar laut. Produktivitas kapal ini dapat mencapai $3000 \mathrm{~m}^{3} / \mathrm{jam}$.

\subsection{Material Keruk}

Material yang akan dikeruk dan diangkut adalah endapan butiran mikro yang mengendap di alur pelayaran. Endapan ini yang menyebabkan pendangkalan pada alr pelayaran sehingga harus dikeruk untuk mendapatkan kedalaman ideal [5]. Untuk meningkatkan efisiensi pengerukan, banyak hal yang dapat dilakukan. Peningkatan tersebut dapat dicapai dengan pemahaman yang lebih baik tentang materi yang akan dikeruk serta pemilihan alat pengerukan yang disesuaikan dengan tipe tanah atau material yang akan dikeruk.

\subsection{Pertimbangan Umum}

Sebelum menghitung produktifitas kapal keruk, perlu dipertimbankan jenis kapal yang dapat mengerjakan pekerjaan ini. Kapal keruk mempunyai spesifikasi dan kemampuan yang berbeda-beda 
sehingga perlu disesuaikan dengan kondisi lapangan. Penentuan jenis kapal keruk yang mampu mengerjakan pekerjaan ini perlu dilakukan di awal. Faktor-faktor yang dilihat meliputi kondisi area keruk, jenis sedimen yang akan dikeruk, produktifitas alat keruk, dan biaya.

\section{METODOLOGI PENELITIAN}

\subsection{Lokasi Penelitian}

Penelitian ini dilaksanakan dengan melakukan analisis perbandingan biaya kapal keruk (dredger) di alur pelabuhan Bandar Bakau Jaya Banten dengan fokus wilayah yang dibatasi pada koordinat $5^{\circ} 57^{\prime} 32.7^{\prime \prime} \mathrm{LS}$ dan $106^{\circ} 06^{\prime} 40.6^{\prime \prime} \mathrm{BT}$ seperti ditunjukkan pada Gambar 2.

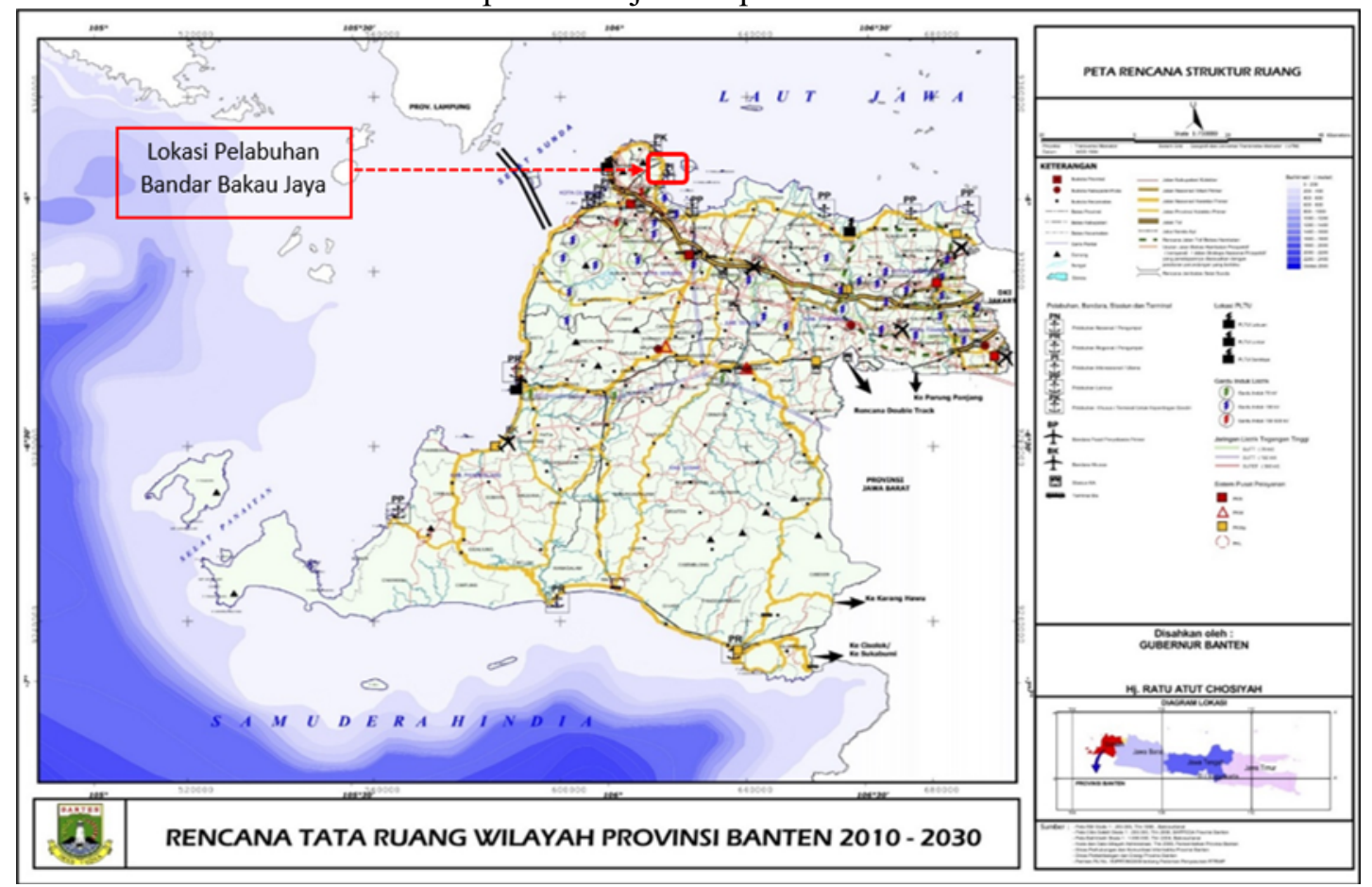

Gambar 2. Peta Rencana Struktur Ruang Wilayah Provinsi Banten [11]

\subsection{Batasan Penelitian}

Batasan-batasan dalam penelitian ini adalah semua data yang diperoleh merupakan data sekunder, penampang alur pelabuhan yang digunakan merupakan hasil penilitian dari Rahman [7], dan pilihan kapal keruk berdasarkan ketersediaan perusahaan di lapangan.

\subsection{Alur Penelitian}

Tahapan yang pertama kali dilakukan dalam penelitian ini adalah merumuskan masalah mengenai adanya pekerjaan pengerukan yang akan dilakukan di alur pelabuhan Bandar Bakau Jaya Banten, yang akan memerlukan perhitungan dalam bentuk waktu dan biaya pelaksanaan. Tahapan selanjutnya adalah studi literatur yang berkaitan dengan rumusan masalah yang telah dibuat. Pengumpulan data yang dilakukan adalah data sekunder. Data sekunder yang didapatkan adalah data batimetri, data tanah, data alur pelabuhan, data layout pelabuhan, dan data jenis-jenis kapal keruk.

Setelah semua data yang berkaitan dengan penelitian terkumpul, tahapan selanjutnya adalah melakukan analisis. Analisis yang dilakukan adalah mengetahui volume total pengerukan yang akan dilakukan di alur Pelabuhan Bandar Bakau Jaya Banten dengan mengetahui jenis tanah yang akan dikeruk. Melakukan perhitungan terhadap masing-masing jenis kapal keruk yang mampu melakukan pekerjaan pengerukan dengan sesuai kondisi di lapangan. Setelah melakukan perhitungan tersebut, didapatkan perbandingan waktu dan biaya pelaksanaan pada pekerjaan pengerukan untuk masingmasing jenis kapal keruk yang ada sehingga dapat diambil kesimpulan kapal keruk mana yang memberikan waktu dan biaya paling murah. 


\section{PEMBAHASAN}

\subsection{Volume Pengerukan}

Dimensi alur pelabuhannya, yaitu 2 jalur, lebar alur adalah $326 \mathrm{~m}$, dan panjang alur total adalah $2.391 \mathrm{~m}$. Berdasarkan hasil pemodelan volume sedimentasi yang telah dilakukan oleh Rahman [7] dengan menggunakan aplikasi pemodelan hidrodinamika 2DH dan menggunakan modul Sand Transport dengan membagi segmen-segmen seperti di Tabel 1:

Tabel 1. Rekapitulasi Sedimentasi Pada Setiap Segmen [7]

\begin{tabular}{lll}
\hline Segmen & $\begin{array}{l}\text { Tinggi } \\
\text { Sedimentasi (m) }\end{array}$ & Lokasi Peninjauan \\
\hline 1 & 0,02582 & Awal Alur Rencana \\
\hline 2 & 0,01743 & Tengah Alur Rencana \\
\hline 3 & 0,006 & Akhir Alur Rencana \\
\hline
\end{tabular}

Panjang total alur adalah sebesar $797 \mathrm{~m}$ dengan lebar $326 \mathrm{~m}$. Didapat total sedimentasi di segmen pertama sebesar 6.708,604 $\mathrm{m}^{3}$ lalu di segmen kedua 4.528,697 $\mathrm{m}^{3}$ dan di segmen terakhir sebesar $1.563,609 \mathrm{~m}^{3}$. Apabila dijumlahkan, total sedimentasi yang mengendap di alur pelabuhan Bandar Bakau Jaya Banten adalah sebesar 12.800,910 m³. Dengan panjang alur $2.391 \mathrm{~m}$ dan lebar $326 \mathrm{~m}$, didapat volume pengerukan sebesar $1.558 .932 \mathrm{~m}^{3}$ sehingga didapatkan volume total pekerjaan pengerukan sebesar $1.571 .732,91 \mathrm{~m}^{3}$.

\subsection{Seleksi Pemilihan Jenis Kapal Keruk}

Berdasarkan data jenis tanah yang ada, komposisi dari sedimen yang terdapat pada alur pelabuhan Bandar Bakau Jaya Banten adalah gravel sebanyak 5,91 \%, sand sebanyak 35,28 \%, slit sebanyak $15,31 \%$, dan clay sebanyak 43,50\%. Dengan demikian, jenis sedimen yang terdapat di alur pelabuhan adalah jenis tanah halus berpasir (clay sand).

Alur pelabuhan berada di daerah terbuka dan dimensi alur yang besar, sehingga jenis kapal yang digunakan harus dapat diangkat dan bergerak serta menggunakan sistem hisap. Analisis seleksi ini dilakukan dengan mengacu pada pendapat Pullar dan Stuart [8], Vlasblom [9], dan jenis tanah serta beberapa informasi yang didapat penulis dari dosen. Berikut adalah tabel matrik kemampuan dari beberapa jenis kapal keruk yang umum digunakan:

Tabel 2. Matriks Kemampuan Jenis Kapal Keruk (dredger)

\begin{tabular}{lllll}
\hline Kapal Keruk & $\begin{array}{l}\text { Kapal Dapat } \\
\text { Diangkat }\end{array}$ & Sistem Hisap & $\begin{array}{l}\text { Mengeruk } \\
\text { Material Pasir }\end{array}$ & $\begin{array}{l}\text { Mengeruk } \\
\text { Material Lanau \& } \\
\text { Lempung }\end{array}$ \\
\hline $\begin{array}{l}\text { Trailing Suction } \\
\text { Hopper Dredger } \\
\text { (TSHD) }\end{array}$ & Mampu & Mampu & Mampu & Mampu \\
\hline $\begin{array}{l}\text { Bucket Ladder } \\
\text { Dredger }\end{array}$ & Tidak Mampu & Tidak Mampu & Mampu & Mampu \\
\hline Grab Dredger & Tidak Mampu & Tidak Mampu & Mampu & Mampu \\
\hline Backhoe Dredger & Tidak Mampu & Tidak Mampu & Mampu & Mampu \\
\hline
\end{tabular}




\begin{tabular}{lllll}
\hline Kapal Keruk & $\begin{array}{l}\text { Kapal Dapat } \\
\text { Diangkat }\end{array}$ & Sistem Hisap & $\begin{array}{l}\text { Mengeruk } \\
\text { Material Pasir }\end{array}$ & $\begin{array}{l}\text { Mengeruk } \\
\text { Material Lanau \& } \\
\text { Lempung }\end{array}$ \\
\hline $\begin{array}{l}\text { Suction Dredger/ } \\
\text { Sand Pump (SD) }\end{array}$ & Mampu & Mampu & Mampu & Mampu \\
\hline $\begin{array}{l}\text { Cutter Suction } \\
\text { Dredger (CSD) }\end{array}$ & Mampu & Mampu & Mampu & Mampu \\
\hline
\end{tabular}

Berdasarkan Tabel 2, ada 3 jenis kapal keruk yang dapat digunakan di alur pelabuhan Bandar Bakau Jaya Banten, yaitu Trailing Suction Hopper Dredger (TSHD), Suction Dredger/Sand Pump (SD), dan Cutter Suction Dredger (CSD).

\subsection{Harga Sewa Kapal}

Harga sewa kapal yang digunakan dalam penelitian ini berdasarkan daftar harga dari perusahaan penyewaan kapal yang didapatkan Rukindo [14], sebagai berikut :

- Trailing Suction Hopper Dredger (TSHD) = Rp2.150.000.000/bulan

- Suction Dredger/Sand Pump (SD) = Rp400.000.000/bulan

- Cutter Suction Dredger (CSD) = Rp1.400.000.000/bulan

- Tugboat dan barge = Rp825.000.000/bulan

\subsection{Lokasi Pembuangan}

Lokasi pembuangan berjarak $20 \mathrm{~km}$ dari lokasi pekerjaan pengerukan. Lokasi dumping area ini dipilih karena sesuai dengan peraturan yang berlaku. Dumping area yang telah dipilih mengikuti aturan yang disebutkan pada Peraturan Menteri Perhubungan No. 52 Tahun 2011 dalam Pasal 5 ayat 5.

\subsection{Contoh Perhitungan Waktu dan Biaya Pelaksanaan Kapal Keruk}

Beberapa data yang dibutuhkan untuk perhitungan jenis kapal keruk Trailing Suction Hopper Dredger (TSHD) ini adalah:

- Produktivitas kapal $=12.500 \mathrm{~m}^{3} / \mathrm{jam}$

- $\operatorname{Daya} \operatorname{mesin}(\mathrm{P})=3.000 \mathrm{Kva}$

- Cycle time

cycle time $=\mathrm{T} \_$keruk $+\mathrm{T} \_$buang

$\mathrm{T}$ keruk $=($ Volume Barge $) /($ Produktivitas Kapal Keruk $)=\left(2.000 \mathrm{~m}^{3}\right) /\left(12.500 \mathrm{~m}^{3} / \mathrm{jam}\right)=0,16 \mathrm{jam}$

T_buang $=2 \times(20.000 \mathrm{~m}) /(4,2 \mathrm{~m} / \mathrm{s})=9523,8 \mathrm{~s}=2,7 \mathrm{jam}$

cycle time $=0,16 \mathrm{jam}+2,7 \mathrm{jam}=2,86 \mathrm{jam}$

- Waktu Pelaksanaan

total cycle time $=2,86$ jam $\times 786$ kali pengangkutan $=2247,96$ jam $\approx 2248$ jam

- Bahan Bakar Minyak (BBM) Kapal Keruk

$\mathrm{bbm}=\mathrm{k} \times \mathrm{P} \times \mathrm{t}=0,21 \times 3.000 \mathrm{Kva} \times 2,86 \mathrm{jam}=1.800$ liter

bbm $=1.800$ liter $\times 786$ kali pengangkutan $\times$ Rp9.600 perliter $=$ Rp13.582.080.000

- Tugboat

$\mathrm{bbm}=\mathrm{k} \times \mathrm{P} \times \mathrm{t}=0,21 \times 300 \mathrm{Kva} \times 2,86 \mathrm{jam}=180$ liter

$\mathrm{bbm}=180$ liter $\times 786$ kali pengangkutan $\times$ Rp9.600 perliter $=$ Rp1.358.208.000

- Biaya Sewa Kapal

$\mathrm{TSHD}=\mathrm{Rp} 2.150 .000 .000 /$ bulan $\times 11$ bulan $=\mathrm{Rp} 23.700 .000 .000$

Tugboat $=$ Rp850.000.000/bulan $\times 1 \times 11$ bulan $=$ Rp9.094.000.000

- Biaya Pelaksanaan

Total biaya pelaksanaan dengan PPN 10\% adalah Rp58.448.000.000,00

Dengan volume pekerjaan pengerukan adalah $1.571 .732,91 \mathrm{~m}^{3}$

Perhitungan ini juga dilakukan terhadap jenis kapal keruk Suction Dredger/Sand Pump (SD) dan Cutter Suction Dredger (CSD). 


\subsection{Analisis Perbandingan Biaya Kapal Keruk dan Tugboat dan Barge}

Dalam menentukan elemen biaya pekerjaan pengerukan, digunakan informasi yang didapatkan dari PT Pengerukan Indonesia (RUKINDO) [10]. Selain itu, penentuan biaya tersebut juga berdasarkan Peraturan Menteri Perhubungan Nomor PM 83 tahun 2011 tentang Standar Biaya Kementerian Perhubungan Tahun Anggaran 2012 [11]. Dikarenakan belum ada batas waktu pekerjaan yang sudah disepakati, penelitian ini memberikan beberapa alternatif pekerjaan pengerukan oleh beberapa jenis kapal keruk dengan menganalisis perbandingan biaya yang digambarkan dalam Grafik 1, Grafik 2, dan Grafik 3 di bawah ini.

\subsubsection{Trailing Suction Hopper Dredger (TSHD) dan Jumlah Tugboat dan Barge}

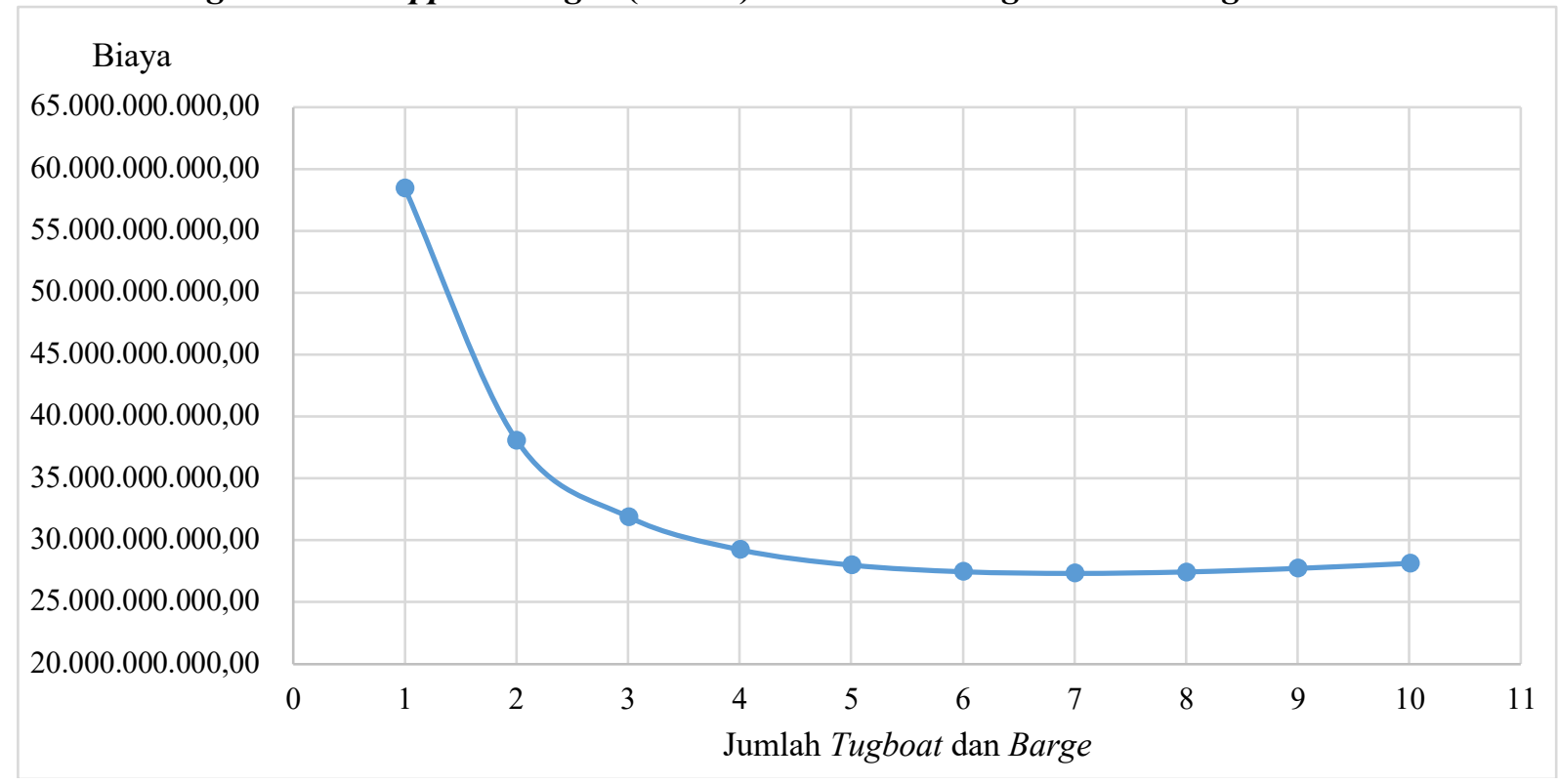

Grafik 1. Pengaruh Jumlah Tugboat dan Barge terhadap Biaya TSHD

Dari Grafik 1 di atas, dapat terlihat bahwa pada pekerjaan pengerukan di alur Pelabuhan Bandar Bakau Jaya Banten dengan menggunakan kapal keruk jenis Trailing Suction Hopper Dredger (TSHD), yang paling efisien adalah gabungan antara 1 Trailing Suction Hopper Dredger (TSHD) dengan 7 tugboat dan barge dengan waktu pelaksanaan selama 2,11 bulan dan total biaya pelaksanaan sebesar Rp27.316.912.819,63. 
4.6.2 Suction Dredger/Sand Pump (SD) dan Jumlah Tugboat dan Barge

Biaya

$65.000 .000 .000,00$

$60.000 .000 .000,00$

$55.000 .000 .000,00$

$50.000 .000 .000,00$

$45.000 .000 .000,00$

$40.000 .000 .000,00$

$35.000 .000 .000,00$

$30.000 .000 .000,00$

$25.000 .000 .000,00$

$20.000 .000 .000,00$

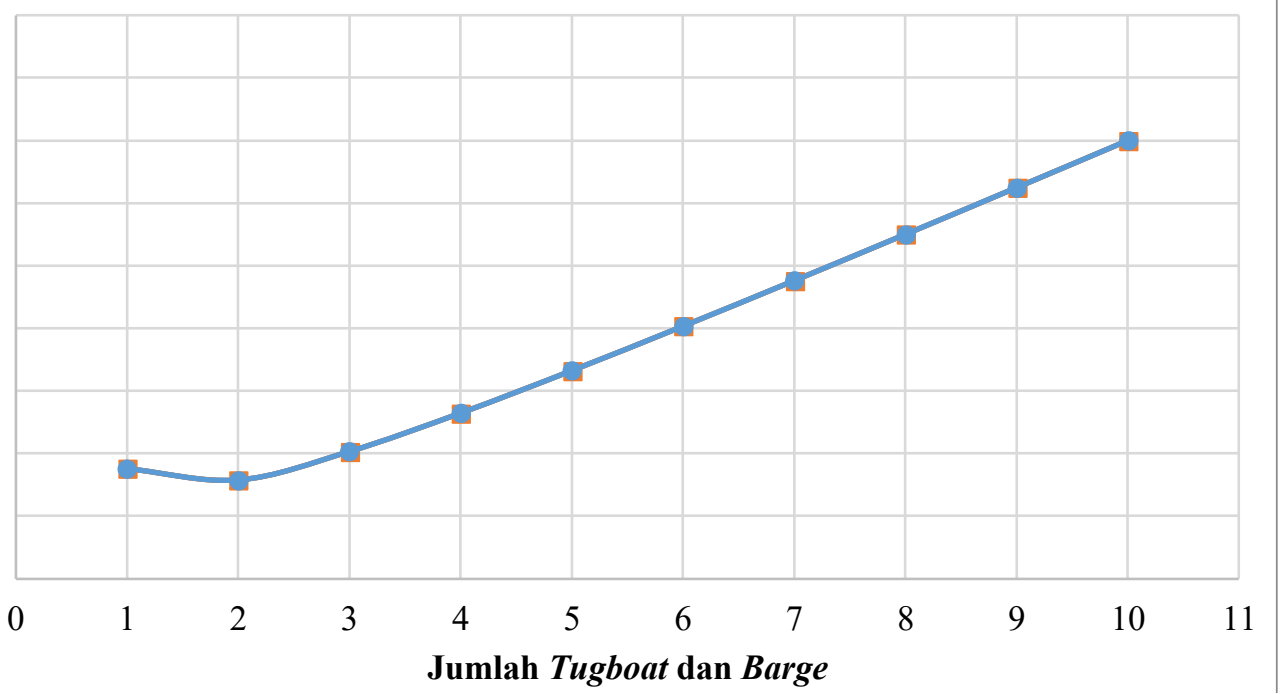

Grafik 2. Pengaruh Jumlah Tugboat dan Barge terhadap Biaya SD

Dari Grafik 2 di atas, dapat terlihat bahwa pada pekerjaan pengerukan di alur Pelabuhan Bandar Bakau Jaya Banten dengan menggunakan kapal keruk dengan jenis Suction Dredger/Sand Pump (SD), yang paling efisien adalah gabungan antara 1 Suction Dredger/Sand Pump (SD) dengan 2 tugboat dan barge dengan waktu pelaksanaan selama 8,34 bulan dan total biaya pelaksanaan sebesar Rp27.887.202.652,35.

\subsubsection{Cutter Suction Dredger (CSD) dan Jumlah Tugboat dan Barge}

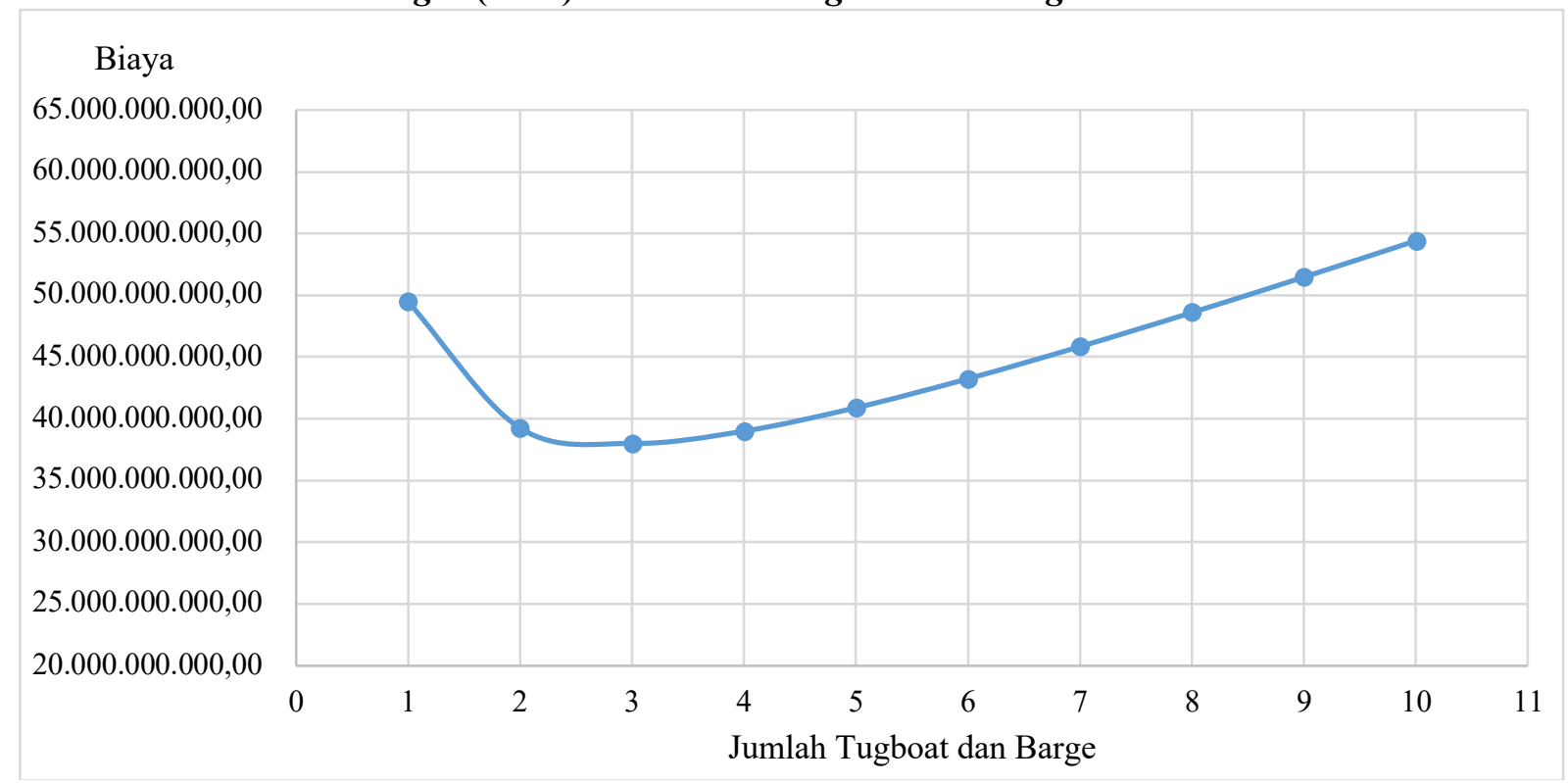

Grafik 3. Pengaruh Jumlah Tugboat dan Barge terhadap Biaya CSD

Dari Grafik 3 di atas, dapat terlihat bahwa pada pekerjaan pengerukan di alur Pelabuhan Bandar Bakau Jaya Banten dengan menggunakan kapal keruk dengan jenis Cutter Suction Dredger (CSD), yang paling efisien adalah gabungan antara 1 Cutter Suction Dredger (CSD) dengan 3 tugboat dan barge dengan waktu pelaksanaan selama 6,08 bulan dan total biaya pelaksanaan sebesar Rp37.995.671.214,00. 


\section{KESIMPULAN}

Total volume pengerukan yang terdapat pada alur Pelabuhan Bandar Bakau Jaya Banten dengan panjang alur $2.391 \mathrm{~m}$ dan lebar $326 \mathrm{~m}$ serta ketebalan pengerukan $2 \mathrm{~m}$ adalah sebesar $1.571 .732,91 \mathrm{~m}^{3}$. Jenis kapal keruk yang dapat mengerjakan pengerukan dengan jenis sedimen clay sand (tanah halus berpasir) pada alur Pelabuhan Bandar Bakau Jaya Banten adalah Trailing Suction Hopper Dredger (TSHD), Suction Dredger/Sand Pump (SD), dan Cutter Suction Dredger (CSD). Jenis kapal keruk yang biayanya paling kecil adalah Trailing Suction Hopper Dredger (TSHD) dengan 7 tugboat dan barge karena hanya membutuhkan waktu pelaksanaan selama 2,11 bulan dan biaya pelaksanaan sebesar Rp27.316.912.819,63 untuk melakukan pekerjaan pengerukan pada alur Pelabuhan Bandar Bakau Jaya Banten. Biaya persatuan volume untuk alternatif yang terpilih dalam pekerjaan pengerukan ini adalah $\mathrm{Rp} 17.380,12 / \mathrm{m}^{3}$.

\section{DAFTAR PUSTAKA}

[1] Fisu, A.A. (2018). "Analisis Kebuthan Fasilitas Sisi Laut Pelabuhan Terminal Khusus PLTGU Lombok", Pena Teknik.

[2] Widodo, W. (2003). “Analisis Teknis Dan Ekonomis Pengadaan Kapal Keruk Yang Sesuai Untuk Pelabuhan Trisakti Banjarmasin”, Institut Teknologi Sepuluh Nopember Repository.

[3] Pamuji, A, dkk. (2015). "Pengaruh Sedimentasi terhadap Kelimpahan Makrozoobenthos di Muara Sungai Betahwalang Kabupaten Demak", Saintek Perikanan.

[4] Triatmodjo, B. (1999). "Teknik Pantai”, Yogyakarta: Beta Offset.

[5] Nurzanah, W. (2019). "Penentuan Lokasi Pembuangan Material Keruk Alur Pelayaran Pelabuhan Belawan dengan Sistem Informasi Geografis", Buletin Utama Teknik Vol. 14 No. 2.

[6] Menteri Perhubungan. (2011). "Peraturan Menteri Perhubungan Nomor PM 83 tahun 2011 Tentang Standar Biaya Kementerian Perhubungan Tahun Anggaran 2012"

[7] Rahman, F. (2018). "Analisis Sedimentasi Bagi Pekerjaan Pengerukan Di Alur Pelabuhan Bandra Bakau Jaya Banten”, Institut Teknologi Nasional.

[8] Yuwono, Endro \& Muhammad Sabaruddin. (2014). "Kajian Pengerukan Waduk Sengguruh Kepanjen Kabupaten Malang”, Politeknik Negeri Balikpapan.

[9] Eisma, D. (2006). "Dredging In Coatal Water", London :Taylor \& Franncis plc.

[10] Bray, Nick, dan Marsha Cohen. (2010). "Dredging For Development. 6th edition", Netherland : International Association of Dredging Companies (IADC).

[11] PT Atlas Primarco. (2016). "SID Pengerukan Alur Pelayaran/Kolam Pelabuhan Tanjung ApiApi Prov. Sumsel”, Bandung.

[12] Pullar, Andy \& Stuart Hughes. (2009). "Dredging Methodology and Disposal Alternatives. New Zealand: Port Otago Ltd."

[13] Vlasblom, Wim. (2003). "Introduction to Dredging Equipment", Netherland: Delft University of Technology.

[14] Rukindo.co.id. (2019, 14 November). "Daftar Harga BBK Tmt 5 Januari 2019”

[15] Menteri Perhubungan. (2011). "Peraturan Menteri Perhubungan Nomor PM 83 tahun 2011 Tentang Standar Biaya Kementerian Perhubungan Tahun Anggaran 2012" 